\title{
Karnofsky Performance Status Unknown
}

National Cancer Institute

\section{Source}

National Cancer Institute. Karnofsky Performance Status Unknown. NCI Thesaurus.

Code C159864.

The Karnofsky Performance Status Score is unknown. 